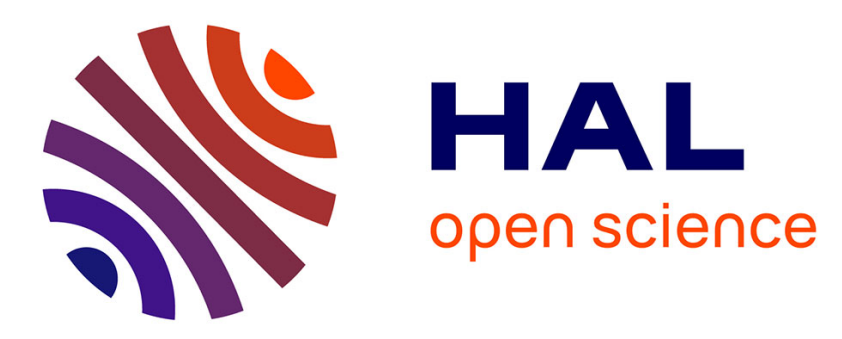

\title{
Niemann-Pick disease type C1 presenting with psychosis in an adolescent male
}

Sabine Sandu, Sabine Jackowski-Dohrmann, Axel Ladner, Michael

Haberhausen, Christian Bachmann

\section{- To cite this version:}

Sabine Sandu, Sabine Jackowski-Dohrmann, Axel Ladner, Michael Haberhausen, Christian Bachmann. Niemann-Pick disease type C1 presenting with psychosis in an adolescent male. European Child and Adolescent Psychiatry, 2009, 18 (9), pp.583-585. 10.1007/s00787-009-0010-2 . hal-00535140

\author{
HAL Id: hal-00535140 \\ https://hal.science/hal-00535140
}

Submitted on 11 Nov 2010

HAL is a multi-disciplinary open access archive for the deposit and dissemination of scientific research documents, whether they are published or not. The documents may come from teaching and research institutions in France or abroad, or from public or private research centers.
L'archive ouverte pluridisciplinaire HAL, est destinée au dépôt et à la diffusion de documents scientifiques de niveau recherche, publiés ou non, émanant des établissements d'enseignement et de recherche français ou étrangers, des laboratoires publics ou privés. 


\title{
Niemann-Pick disease type $\mathrm{C} 1$ presenting with psychosis in an adolescent male
}

\author{
Sabine Sandu • Sabine Jackowski-Dohrmann · \\ Axel Ladner · Michael Haberhausen · \\ Christian Bachmann
}

Received: 15 March 2008/Accepted: 16 February 2009/Published online: 7 March 2009

(C) Springer-Verlag 2009

\begin{abstract}
Niemann-Pick disease, a neurovisceral lysosomal lipid storage disorder, is a rare disorder that is unknown to many clinicians. The disease, that often has its onset during childhood or adolescence, shows a polymorphic clinical picture, including psychiatric symptoms. Because of its infrequence, Niemann-Pick disease is diagnosed with an average delay of 6 years. This report presents a case of an adolescent male whose symptoms had led to various hospitalisations and psychiatric diagnoses. When he presented with psychotic symptoms in our department, thorough diagnosis revealed Niemann-Pick disease type C1 as the underlying disease.
\end{abstract}

Keywords Adolescence - Niemann-Pick disease · Organic psychosis $\cdot$ Sphingomyelin lipidosis

\section{Introduction}

Niemann-Pick disease type C (NPC), first described by Niemann in 1914 [6] and characterized with its pathology by Pick in 1933 [9], is a fatal neurovisceral lysosomal lipid storage disorder of autosomal recessive inheritance with a birth prevalence of 1:100,000 live births. Biochemically and phenotypically, it is different from Niemann-Pick diseases types $\mathrm{A}$ and $\mathrm{B}$, which are characterized by lysosomal sphingomyelinase deficiency. On a cellular level,

S. Sandu - S. Jackowski-Dohrmann · A. Ladner .

M. Haberhausen · C. Bachmann $(\square)$

University Hospital Giessen and Marburg,

Campus Marburg, Marburg, Germany

e-mail: christian.bachmann@charite.de

C. Bachmann

Charité, Universitätsmedizin Berlin, Berlin, Germany
NPC is characterized by accumulation of unesterified cholesterol and glycolipids in the endosomal/lysosomal system [7], due to an inactivating mutation of NPC1 protein, which normally aids movement of unesterified cholesterol from the endosomal/lysosomal compartment to the cytosolic compartment. The symptomatology, which generally encompasses hepatosplenomegaly, cerebellar ataxia, dysarthria, vertical gaze palsy, cognitive difficulties and progressive neurological deterioration, is polymorphic with various epiphanies and great variety in the progress [2, 10]. NPC is difficult to diagnose, particularly when it presents as a pure psychiatric disorder $[1,4,10]$.

Psychiatric signs associated with NPC may remain isolated for several years and are usually consistent with psychotic symptoms (e.g. paranoid delusions, auditory or visual hallucinations, interpretative thoughts) and behavioural disturbances like aggressiveness, self-mutilation or social isolation [10].

Presently, the treatment of NPC is restricted to symptomatic measures. Causal therapeutic approaches, which include substrate reduction therapy [8], reversal of lysosomal transport [5] or stem cell transplantation (e.g. NCT00176904, http://clinicaltrials.gov, accessed 31.01.2009), are still in a pre-clinical stage or limited to small preliminary trials.

\section{Case report}

We present the case of a 17-year-old male, who was admitted to our child and adolescent psychiatric ward with the diagnosis of paranoid schizophrenia. Under treatment with quetiapine $(1,000 \mathrm{mg} / \mathrm{d}$, no side effects), he still suffered from productive symptoms such as auditory and visual hallucinations and content-thought disorders. 
Interestingly, the patient had a long history of physical and psychiatric problems. The first medical conspicuity was neonatal jaundice. His motor development was delayed; he had difficulties to tie his shoes and to use zips. Language acquisition was significantly late. A speech therapy at 3 years of age was discontinued as it showed no effect. Later on, behavioural disturbances were noticed, including a tendency towards social isolation, stereotypic occupations, obsessive-compulsive practices as well as aggressive tendencies.

At the age of 7 , the patient temporarily experienced auditory hallucinations. At the age of 8 he was presented to a child and adolescent psychiatrist for the first time, due to substantial learning difficulties and emotional problems. A HAWIK-R intelligence test revealed a result in the lower average range. Additionally, the diagnosis of an isolated reading and writing disorder was made. Simultaneously, a splenomegaly was diagnosed, which was considered to be a persistent splenomegaly after an Epstein-Barr virus infection.

At the age of 13, an absence epilepsy (abnormal EEG and observation of absences with fixed gaze and lack of response for a 2-year period) was diagnosed and successfully treated with valproic acid.

As symptoms persisted, at the age of 14 years the patient was referred to a social paediatric center where a pervasive development disorder was diagnosed based upon significant results in specific autism tests [Autism Diagnostic Interview Revised (ADI-R) and Autism Diagnostic Observation Schedule-Generics (ADOS-G)]. Additionally, due to recurrent headaches with vomiting, infantile migraine was diagnosed. Besides significantly impaired motor functions, the patient also presented a mild dysdiadochokinesia and slurred speech. A genetic analysis for fragile $\mathrm{X}$ syndrome and chromosomal abnormalities and a subtelomere screening were carried out, showing no pathological results.

At the age of 16, emergency hospitalisation was necessary after 2 months of increasing content-thought abnormality, including paranoia, visual and auditory hallucinations. Furthermore, formal-thought disorders, disorientation to all qualities, a labile affect and an abnormal gait were present. After 4 months of antipsychotic treatment with risperidone ( $2.5 \mathrm{mg} / \mathrm{d}$, no side effects reported), visual and auditory hallucinations ceased and orientation recovered. The patient was discharged with the diagnoses of a transient psychotic episode and Asperger's syndrome.

Three months later, the then 17-year-old adolescent was admitted to the child and adolescent psychiatric department again. This time, he presented with symptoms of temporal disorientation, content- and formal-thought disorders, significant dysmnesia, impaired concentration and dysarthria. Additionally, he showed stand and gait ataxia.
Subsequently, antipsychotic therapy was switched from risperidone to quetiapine (final dose: $1,000 \mathrm{mg} / \mathrm{d}$, no side effects). Under this treatment, psychotic symptoms improved and the patient was discharged with the diagnoses of paranoid schizophrenia and Asperger's syndrome.

Subsequently, due to the above-reported motor and coordinative abnormalities and dysarthria, he was presented to a neuropediatric outpatient clinic, where the suspected diagnosis of a cerebellar disorder was made. A cerebral MRI showed no pathologies at this time.

About 1 month later, the patient was admitted to our child and adolescent psychiatry ward for comprehensive diagnostic analysis. Due to the neurological abnormalities mentioned before, the patient was sent to the neuropediatric department for a diagnostic investigation with the suspicion of an organic psychosis. The neurological examination revealed ataxia, dysarthria, mild dysdiadochokinesia, inability to stand up from lying without bracing, a mild paresis of the peroneal nerve, slightly reduced motor strength, particularly broadened reflex zones and a strong rebound phenomenon. Vertical gaze palsy, a characteristic diagnostic sign in the majority of NPC patients, was not present. The physical examination revealed the already known splenomegaly. Under the suspected diagnosis of Niemann-Pick disease, a fibroblast culture was installed, which showed positive filipin staining, thus proving the diagnosis. Further molecular genetic testing revealed two mutations in exons 13 and 19 of the NPC1 gene on chromosome 18q, confirming NiemannPick disease subtype $\mathrm{C} 1$.

During the stay on our ward, the patient developed paranoia and aggressive impulses against other patients. For this reason, the antipsychotic treatment with quetiapine (1,000 $\mathrm{mg} / \mathrm{d})$ was augmented with haloperidol $(10 \mathrm{mg} / \mathrm{d})$ in combination with biperiden $(4 \mathrm{mg} / \mathrm{d})$, resulting in a considerable improvement of psychopathology and disappearance of productive psychotic symptoms. Side effects were not reported. Unfortunately, during the course of his hospital stay, the patient's physical health deteriorated significantly; the maximum walking distance decreased to $200 \mathrm{~m}$ and he had to use a wheelchair for longer distances. After 4 months of inpatient treatment, the patient was discharged to an institution for children and adolescents with chronic physical and mental health problems.

\section{Discussion}

Because of its infrequency, NPC is diagnosed with an average delay of $6.2( \pm 6.4)$ years [10]. Our case demonstrates that, particularly when associated with psychiatric symptoms, the course towards a correct diagnosis may take even longer. Furthermore, accompanying unspecific 
symptoms like learning difficulties may also lead to misdiagnoses.

Admittedly, the association of psychiatric symptoms and NPC does not necessarily establish a causal link between both entities. However, when taking into account the considerable rates of psychiatric symptoms (general psychiatric symptoms in early adulthood in $38 \%$ of patients [10], history of psychotic symptoms in $35 \%$ of young adult patients [3]) described in case series of NPC patients, in the above-reported case a causal relationship between NPC and psychotic symptoms appears most likely.

In conclusion, in patients with psychotic symptoms and especially in those with additional motor and cognitive impairments, every child and adolescent psychiatrist should be aware of the possibility of an organic psychosis. In those cases, a thorough differential diagnostic and assessment, including also quite infrequent disorders, is of utmost importance [11].

\section{References}

1. Campo JV, Stowe R, Slomka G, Byler D, Gracious B (1998) Psychosis as a presentation of physical disease in adolescence: a case of Niemann-Pick disease, type C. Dev Med Child Neurol 40:126-129

2. Garver WS, Francis GA, Jelinek D, Shepherd G, Flynn J, Castro G, Walsh Vockley C, Coppock DL, Pettit KM, Heidenreich RA, Meaney FJ (2007) The national Niemann-Pick C1 disease database: report of clinical features and health problems. Am J Med Genet Part A 143:1204-1211

3. Imrie J, Vijayaraghaven S, Whitehouse C, Harris S, Heptinstall L, Church H, Cooper A, Besley GT, Wraith JE (2002) NiemannPick disease type $\mathrm{C}$ in adults. J Inherit Metab Dis 25:491-500

4. Josephs KA, Van Gerpen MW, Van Gerpen JA (2003) Adult onset Niemann-Pick disease type $\mathrm{C}$ presenting with psychosis. J Neurol Neurosurg Psychiatry 74:528-529

5. Liu B, Turley SD, Burns DK, Miller AM, Repa JJ, Dietschy JM (2009) Reversal of defective lysosomal transport in NPC disease ameliorates liver dysfunction and neurodegeneration in the npc1-/- mouse. Proceedings of the National Academy of Sciences of the United States of America Jan 26 (Epub ahead of print)

6. Niemann A (1914) Ein unbekanntes Krankheitsbild. Jahrbuch der Kinderheilkunde 1

7. Patterson MC, Vanier MT, Suzuki K, Morris JA, Carstea ED, Neufeld EB, Blanchette-Mackie EJ, Pentchev PG (2001) Niemann-Pick disease type C, a lipid trafficking disorder. In: Scriver CR, Beaudet AL, Sly WS, Valle D, Childs B, Kinzler KW, Vogelstein B (eds) The metabolic and molecular bases of inherited diseases, 8th edn. McGraw-Hill, New York, pp 3611-3634

8. Patterson MC, Vecchio D, Prady H, Abel L, Wraith JE (2007) Miglustat for treatment of Niemann-Pick C disease: a randomised controlled study. Lancet Neurol 6:765-772

9. Pick L (1933) Niemann-Pick's disease and other forms of so called xanthomatosis. Am J Med Sci 185:601-616

10. Sévin M, Lesca G, Baumann N, Millat G, Lyon-Caen O, Vanier MT, Sedel F (2007) The adult form of Niemann-Pick disease type C. Brain 130:120-133

11. Walterfang M, Fietz M, Fahey M, Sullivan D, Leane P, Lubman DI, Velakoulis D (2006) The Neuropsychiatry of Niemann-Pick Type $\mathrm{C}$ disease in adulthood. J Neuropsychiatry Clin Neurosci 18:158-170 